\title{
Hubungan Wayang dan Gending dalam Pakeliran Wayang Kulit Purwa Gaya Surakarta
}

\author{
Junaidi dan Asal Sugiarto \\ Jurusan Pedalangan FSP Institut Seni Indonesia Yogyakarta \\ Email: junaidi.skar@yahoo.com
}

\begin{abstract}
Dalang when displaying the puppet characters are always supported by the musical, so the concept of relationship must be known in order to avoid incorrect installation. During this time, only disclosed the names, shapes, make signs, playing with, notations balungan, and functions, but the underlying reasons association has not been described in detail, resulting in the replacement of the pair resulting in the incongruity and crisis gending pakeliran knowledge and techniques. The goal is to know about the underlying reason for the installation of a puppet with the musical in every scene. The method used is descriptive identification, based on the literature data and field observations, while the discussion used the theory of functions gending in pakeliran, namely as an illustration, framed, and unifying. The result is the installation of a puppet with the musical based on the shape and character.
\end{abstract}

Keywords: relationship; puppet; gending; pakeliran; style of Surakarta

\begin{abstract}
Abstrak
Dalang ketika menampilkan tokoh wayang selalu didukung oleh gending, sehingga konsep hubungannya harus diketahui agar tidak terjadi salah pemasangan. Selama ini, hanya diungkapkan tentang nama-nama, bentuk, tanda isyarat, garap, notasi balungan, dan fungsinya, tetapi alasan yang mendasari keterkaitannya belum dijelaskan secara detail, sehingga terjadi penggantian pasangan yang berakibat pada ketidaksesuaian dan krisis pengetahuan serta teknik gending pakeliran. Tujuan tulisan ini adalah ingin mengetahui tentang alasan yang mendasari pemasangan wayang dengan gending dalam setiap adegan. Metode yang digunakan adalah penelitian deskriptif identifikasi, berdasarkan data pustaka dan pengamatan lapangan, sedangkan pembahasannya digunakan teori fungsi gending dalam pakeliran, yaitu sebagai ilustrasi, pembingkai, dan penyatu. Hasilnya berupa pemasangan wayang dengan gending berdasarkan bentuk dan karakter.
\end{abstract}

Kata kunci: hubungan; wayang; gending; pakeliran; gaya Surakarta

\section{Pendahuluan}

Dalang sebagai pemain utama dalam pertunjukan wayang dituntut menguasai unsur-unsur material garap pakeliran yang terdiri atas: lakon, catur, sabet, sulukan, tembang, keprakan, dhodhogan, dan gendhing. Lakon diartikan cerita pokok atau kisah yang terjadi, dengan konsep dan teknik penyajiannya terbagi menjadi tiga babak atau bagian (pathet), yaitu: pathet nem, pathet sanga, dan 
pathet manyura, sedangkan adegan yang ditampilkan meliputi: jejer, babak unjal, kondur kedhaton, gapuran, kedhatonan, paséban jawi, budhalan prajurit, sabrangan, miji punggawa, budhalan sabrangan, prang gagal, magakan, budhalan, gara-gara, sanga sepisan, budhalan bambangan, alas-alasan, prang kembang, sintrèn, budhalan sintrèn, prang sintrèn, manyura sepisan, prang manyura, manyura kalih, prang brubuh, dan tancep kayon.

Catur adalah susunan atau rangkaian bahasa yang diucapkan, berisi tentang pelukisan sesuatu keadaan atau yang berupa percakapan wayang, terdiri tiga bagian, yaitu: janturan, pocapan, dan ginem (Suyanto, 2007: 10). Janturan merupakan wacana dalang berupa deskripsi suatu adegan yang sedang berlangsung, di dalam gending sirep. Pocapan adalah wacana dalang berupa narasi yang pada umumnya menceritakan peristiwa yang sudah, sedang, dan akan berlangsung, diiringi dengan grimingan gender. Ginem berarti percakapan tokoh wayang baik berbentuk monolog dan dialog. Macam-macam catur disesuaikan dengan adegan yang dimunculkan, sehingga menjadi istilah perpaduan, seperti misalnya: catur jejer, catur babak unjal, catur kondur kedhaton, catur gapuran, catur kedhatonan, catur paséban jawi, catur budhalan prajurit, dan sebagainya.

Sabet adalah semua bentuk penampilan wayang meliputi: cepengan, bedholan, metonan, tancepan, solah, dan entas-entasan (Junaidi, 2014: 9). Cepengan adalah teknik memegang boneka wayang, meliputi: methit, nglenkèh, micis, ngepok, njagal, dan ngrogoh. Bedholan merupakan teknik mengangkat atau mencabut wayang dari panggungan. Metonan adalah teknik memunculkan tokoh wayang di jagadan. Tancepan adalah teknik meletakkan atau menancapkan boneka wayang di debogan. Solah merupakan aktivitas gerakan wayang di jagadan. Entas-entasan merupakan penarikan tokoh wayang dari jagadan.

Sulukan merupakan nyanyian dalang untuk mendukung suasana adegan (Probohardjono, 1966: 11). Jenis sulukan ada tiga, yaitu: pathetan, ada-ada, dan sendhon, sedangkan jumlahnya mencapai 46 (empat puluh enam macam), yaitu: Pathet Nem Ageng, Ada-ada Girisa Wantah, Adaada Girisa Jugag, Pathet Nem Wantah, Pathet Nem Jugag, Sendhon Pananggalan, Sendhon Kloloran, Ada-ada Hastakuswala Alit, Ada-ada Hastakuswala
Ageng, Ada-ada Budhalan Mataraman, Ada-ada Gregetsaut Mataraman Wantah, Ada-ada Gregetsaut Mataraman Jugag, Pathetan Kedhu, Pathetan Lindur, Pathetan Lasem, Sendhon Tlutur Wetah Nem, Ada-ada Girisa Yaksa, Pathetan Sanga Wantah, Pathetan Sanga Ngelik, Pathetan Sanga Jugag, Adaada Gregetsaut Manggalan, Ada-ada Gregetsaut Tlutur, Sendhon Recansih, Sendhon Tlutur Wetah Sanga, Sendhon Tlutur Wantah Sanga, Ada-ada Gregetsaut Werkudara Mlumpat, Ada-ada Gregetsaut Gathutkaca, Ada-ada Gregetsaut Wanawasa, Ada-ada Gregetsaut Palaran, Ada-ada Hastakuswala Sanga, Pathet Jingking, Pathet Sendhon Bimanyu, Pathet Manyura Wantah, Pathet Manyura Jugag, Sendhon Tlutur Wantah, Ada-ada Gregetsaut Gathutkaca, Ada-ada Gregetsaut Manyura Wantah, Ada-ada Gregetsaut Manyura Jugag, Pathetan Manyura Ageng, Pathetan Manyura Ngelik, Sendhon Sastradatan, Ada-ada Gregetsaut Werkudara Mlumpat, Ada-ada Gregetsaut Tlutur, dan Sendhon Kagokkatanon.

Tembang adalah nyanyian yang difokuskan pada adegan gara-gara yang ditengarai dengan kemunculan tokoh panakawan Semar, Gareng, Petruk, dan Bagong, dan atau adegan kedhatonan yang ditengarai dengan munculnya tokoh wayang abdi perempuan Cangik dan Limbuk (Limbukan). Repertoar ini disebut dengan tembang/lagu/gending dolanan, yaitu sekelompok nyanyian yang bersifat hiburan, bahkan meluas fungsinya, yakni sebagai media hiburan kepada penonton. Tembang dolanan dalam pakeliran tradisi sangat terbatas, antara lain: Dhandhanggula Céngkok Macapat, Gérong Kinanthi Ketawang Subakastawa, Gambub Céngkok Palaran, Céngkok Langengita, Ketawang Puspagiwang, Lagu Canthing Gléyong, dan sebagainya, sedangkan dalam perkembangan selanjutnya bermunculan lagu-lagu dolanan, seperti: Caping Ggunung, Kelici Ucul, Sri Huning, Mendem Wédokan, Begadhang, Prau Layar, Mas Aja Dipléroki, Aja Lamis, dan sebagainya yang jumlahnya mencapai ratusan lagu.

Keprakan adalah suatu bunyi yang ditimbulkan dari susunan logam tergantung di kotak oleh sepakan kaki kanan dalang, dengan posisi duduk sila tumpang (dijejakldipancal), sedangkan dhodhogan adalah bunyi yang ditimbulkan dari kotak karena dipukul dengan cempala oleh tangan dalang. Macam-macam keprakan antara lain: lamba, geterl ganter, minjal, rangkep, manyar ngloloh, nyisir, dan gejogan, sedangkan macam-macam dhodhogan 
meliputi: lamba, geter/ganter, minjal, rangkep, dan banyu tumètes. Keprakan dan dhodhogan berfungsi sebagai penguat suasana, tanda perintah, tanda irama, dan sebagainya. Gending adalah istilah lagu dalam musikal gamelan, sedangkan gending wayangan, yaitu gending-gending yang biasa digunakan untuk mendukung pertunjukan wayang (Supanggah, 2009: 133).

Kemunculan setiap tokoh wayang selalu didukung dengan gending, baik secara individual dan kolektif. Pemasangan secara individual yaitu setiap tokoh wayang memiliki repertoar gending tersendiri, seperti misalnya Prabu Duryudana memakai Ketawang Gendhing Kabor laras slendro pathet nem (Nojowirongko, 1960: 34, Probohardjono, 1957: 24, Panenggak Widada, 1975: 6, Walidi, 1977: 13, dan Wignyosoetarno, 1977: 1). Batara Guru dan Prabu Puntadewa memakai Ketawang Gendhing Kawit laras slendro pathet manyura (Panenggak Widada, 1975: 6, dan Nojowirongko, 1960: 34), sedangkan pemasangan secara kolektif adalah sekelompok tokoh memiliki salah satu repertoar untuk digunakan bersama, seperti misalnya Prabu Kresna, Prabu Baladewa, Prabu Basukestiwara, Prabu Basudewa, Prabu Salya, Prabu Drupada, dan lainnya (selain Prabu Duryudana, Prabu Puntadewa, dan Batara Guru) menggunakan Ketawang Gendhing Karawitan laras slendro pathet nem (Panenggak Widada, 1975: 50, Kusumadilaga, 1981: 70, dan Walidi, 1977: 17).

Melihat realitas ini, ditemukan konsep pemasangan antara wayang dan gending, sehingga setiap tokoh wayang telah memiliki gending sendiri-sendiri. Tentu saja pemasangannya memiliki alasan secara estetik, teknik, dan filosofi, sehingga pembakuan ini dilakukan. Tokoh wayang kulit purwa gaya Surakarta satu set berjumlah \pm 360 an (tiga ratus enam puluhan) memiliki bentuk dan karakter berbeda-beda, sehingga gending pendukungnya juga berbeda-beda pula. Gending di dalam pakeliran bersifat mungkus (membingkai), nglambari (ilustrasi), dan nyawiji (Waridi, 2005: 17-59). Namun demikian, sejauh ini belum ditemukan penjelasan mengenai hubungan antara wayang dengan gending pendukungnya. Di mana korelasi antara tokoh wayang dengan gending pendukungnya? Untuk mendapatkan jawaban atas pertanyaan ini akan dilakukan pengkajian agar fenomena ini dapat dijelaskan secara logis, kepada masyarakat karawitan dan pedalangan, khususnya yang menganut gaya Surakarta.

\section{Tokoh Wayang dengan Gending Pendukungnya}

Marwata Panenggak Widada (1975), Kusumadilaga (1981), Nojowirongko (1960), dan Wignyasoetarno (1977), menuliskan berbagai tokoh wayang dengan gendingnya dalam balungan dan naskah lengkapnya. Marwata Panenggak Widada (1975) dalam salah satu balungan lakon Pandhawa Gupak menyebutkan bahwa Prabu Duryudana di Negara Astina didukung dengan Ketawang Gendhing Kabor, Raden Nagkula dalam adegan babak unjal didukung dengan Ladrang Kembang Pépé, Prabu Duryudana jengkar ngedhaton didukung Ayak-Ayakan, Prabu Duryudana dalam adegan gapuran didukung Ayak-Ayakan Panjang Mas, Dewi Banowati di taman Kadilengleng adegan kedhatonan didukung dengan Gendhing Damarkèli, Raden Nangkula dalam adegan pasowanan jawi didukung dengan Gendhing Prihatin, Prampogan atau sekelompok prajurit dalam adegan budhalan didukung dengan Lancaran Kebogiro. Prabu Kresna di Negara Dwarawati dalam adegan sabrangan didukung dengan Gendhing Bujangga. Prabu Puntadewa di Negara Ngamarta dalam adegan magakan didukung dengan Gendhing Renyep, Prajurit yang sedang bertempur dalam adegan prang gagal didukung dengan Srepegan, Resi Abiyasa dihadap Raden Abimanyu di Pertapan Saptaarga dalam adegan sanga sepisan didukung dengan Gendhing Gambirsawit, Cakil dan rekan-rekannya dalam adegan alas-alasan didukung dengan Ladrang Kagok Madura, Prabu Baladewa di Negara Mandura dalam adegan sintrèn didukung dengan Ladrang Pangkur, Batara Guru di Kayangan dalam adegan manyura sepisan didukung dengan Ladrang Sumirat, Prabu Duryudana di Negara Astina dalam adegan manyura kalih didukung dengan Ladrang Kandha Manyura, Prabu Puntadewa dalam adegan tancep kayon didukung dengan Ladrang Manis.

Nojowirongko (1960) dalam naskah pakeliran lengkap atau pakem jangkep lakon Irawan Rabi, menampilkan Prabu Kresna di Negara Dwarawati dalam jejer didukung dengan Gendhing Karawitan, Prabu Baladewa dalam adegan babak unjal didukung dengan Ladrang Remeng, Prabu Kresna 
dalam bedholan jejer didukung dengan AyakAyakan, Prabu Kresna dalam adegan gapuran didukung dengan Ayak-Ayakan Panjangmas, Dewi Jembawati, Dewi Rukmini, dan Dewi Setyaboma di kaputren Dwarawati dalam adegan kedhatonan didukung dengan Gendhing Titipati, Raden Samba di Negara Dwarawati dalam adegan pasowanan jawi, didukung dengan Gendhing Kedhaton Bentar, Prajurit Dwarawati dalam budhalan didukung dengan Lancaran Kebogiro, Prampogan dalam adegan prang ampyak didukung dengan Srepegan, Prabu Baranjana di Negara Jongbiraji dalam adegan sabrangan didukung Gendhing Majemuk, Pralemba dalam adegan miji punggawa didukung dengan Ladrang Bedhat, Prajurit raksasa dalam budhalan didukung dengan Srepegan Pinjalan, Prajurit dalam prang gagal didukung dengan Srepegan, Raden Werkudara di Kasatriyan Munggul Pamenang dalam adegan magakan didukung dengan Ladrang Babatkenceng, Raden Werkudara dalam budhalan didukung dengan Srepegan, Begawan Kano dihadap oleh Bambang Irawan di Pertapan Yasarata dalam adegan sanga sepisan didukung dengan Ladrang Sumedhang, Irawan dalam adegan alas-alasan didukung dengan Ayak-Ayakan, Cakil dan kawankawannya dalam adegan alas-alasan didukung dengan Lancaran Jangkrik Génggong, Irawan dengan Cakil dalam prang kembang didukung dengan Srepegan, Raden Arjuna di Kasatriyan Madukara dalam adegan sampak tanggung didukung dengan Gendhing Gambirsawit, Raden Abimanyu dengan Siti Sendari dalam adegan sintrèn didukung dengan Ladrang Kembang Tanjung, Raden Abimanyu jatuh pingsan didukung dengan Ayak-Ayakan Tlutur, Prabu Baranjana di Negara Jongbiraji dalam adegan sampak tanggung didukung dengan Gendhing Galagotang, Prabu Duryudana di Negara Astina dalam adegan manyura sepisan didukung dengan Gendhing Gliyung, Prabu Kresna di Negara Dwarawati dalam adegan manyura kalih didukung dengan Gendhing Ramyang, Prabu Baranjana di Negara Jongbiraji dalam adegan manyura tiga didukung dengan Lancaran Ricik-Ricik untuk mengiringi adegan manyura tiga, Prabu Puntadewa di Negara Amarta dalam adegan manyura sekawan didukung dengan Gendhing Bang-Bang Wétan, Prajurit dalam adegan prang manyura sepisan didukung dengan Srepegan, Prajurit dalam prang sampak,amuk-amukan/prang brubuh didukung dengan Sampak, dan Prabu Puntadewa di Negara Amarta dalam adegan tancep kayon didukung dengan Ladrang Manis.

Tokoh wayang yang ditampilkan dalam setiap adegan kaitannya dengan gending pendukungnya, jika dicermati tampak adanya korelasi. Tokoh Duryudana misalnya ketika ditampilkan dikelir pada waktu jejer iringan yang mendukungnya ialah Ketawang Gending Kabor. Wujud wayang tokoh Duryudana dapat dilihat pada gambar 1. Kata kabor identik dengan bobor atau jébor artinya setengahsetengah atau tidak jadi, sedangkan karakter Prabu Duryudana antara lain: sombong dan ragu-ragu, sehingga sering mendapatkan kegagalan dalam meraih sesuatu yang dicita-citakan (Junaidi, 2011: 33). Ditinjau dari pengertian gending dan tokoh wayang terdapat korelasi sifat atau karakter gending dengan tokoh wayang yang sama-sama berkarakter ragu-ragu, setengah-setengah, dan tidak jadi atau tercapai. Dalam hal ini Prabu Duryudana seorang raja yang mudah diperdaya oleh punggawanya, tidak pernah tercapai apa yang diinginkan, contohnya ketika menginginkan wahyu makutharama ia tidak mendapatkannya. Adapun notasi balungan gending Kabor dapat dilihat seperti berikut:

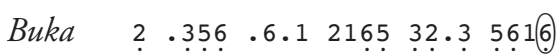

$$
\begin{aligned}
& \text { Mérong .2.2 .2.3 56i. 56î́ } 55 \ldots 56535653 \quad 216(5) \\
& .555 \quad 2235 \quad 235621650 \text { 33.. } 3353 \quad 6535 \quad 3212 \\
& \begin{array}{llllllll}
.5 .3 & .5 .2 & .5 .3 & .5 .2 & 55 \ldots 53 & 5653 & 216(5)
\end{array} \\
& \text { Ngelik 66.. } 5556 \text { ii.. 32i்) (Walidi, 1977: 13) }
\end{aligned}
$$

Contoh lain Gendhing Damarkèli untuk mengiringi Dewi Banowati ketika bertemu dengan Prabu Duryudana di taman Kadilengeng/ Kadilengleng. Kata damarkèli berasal dari dua kata yaitu "damar" artinya lampu atau pelita/diyan, dan "kèli" artinya hanyut/kéntir. Maksudnya lampu yang hanyut di atas air, yakni memiliki suasana yang mengkhawatirkan atau penuh hati-hati, karena jika bergoyang bahkan jatuh maka matilah api lampu tersebut. Sama halnya dengan suasana hati Dewi Banowati ketika berhadapan dengan Prabu Duryudana sang suami, yakni bersifat pura-pura/ lamis karena tidak memiliki cinta. Putri tersebut hanya mencintai Arjuna musuh Prabu Duryudana, maka posisi Dewi Banowati berada di Astina demi membela Arjuna dengan cara menyusupkan diri 
di dalam lingkungan musuhnya, sehingga harus hati-hati penuh dengan waspada. Jika lengah sedikit saja akan mendapat kesulitan. Dengan demikian, posisi Dewi Banowati ketika bertemu dengan Prabu Duryudana bagaikan lampu terseret air, yakni dalam posisi mengkhawatirkan. Oleh karena itu, tokoh wayang yang digunakan pun juga disesuikan, yaitu memakai Dewi Banowati wanda golèk (boneka kayu), maksudnya berwujud cantik tetapi tidak dapat dinikmati, seperti wujud fisik Dewi Banowati yang cantik tersebut ketika bertemu dengan suaminya Prabu Duryudana menjadi friginitas (dingin tanpa nafsu). Wujud wayang tokoh Banowati wanda golèk dapat dilihat pada gambar 2. Tentu saja rasa khawatir tersebut tidak ditampakkan secara fisik, agar penyamarannya tercapai dengan baik. Adapun notasi balungan gending dan foto boneka wayang Dewi Banowati dapat dilihat pada gambar 2 .

$\begin{array}{llllllll}\text { Buka } \quad 3 & .561 & .1 .1 & .2 .3 & .212 & .12(6)\end{array}$

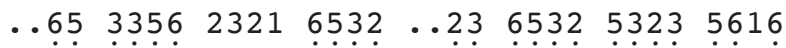

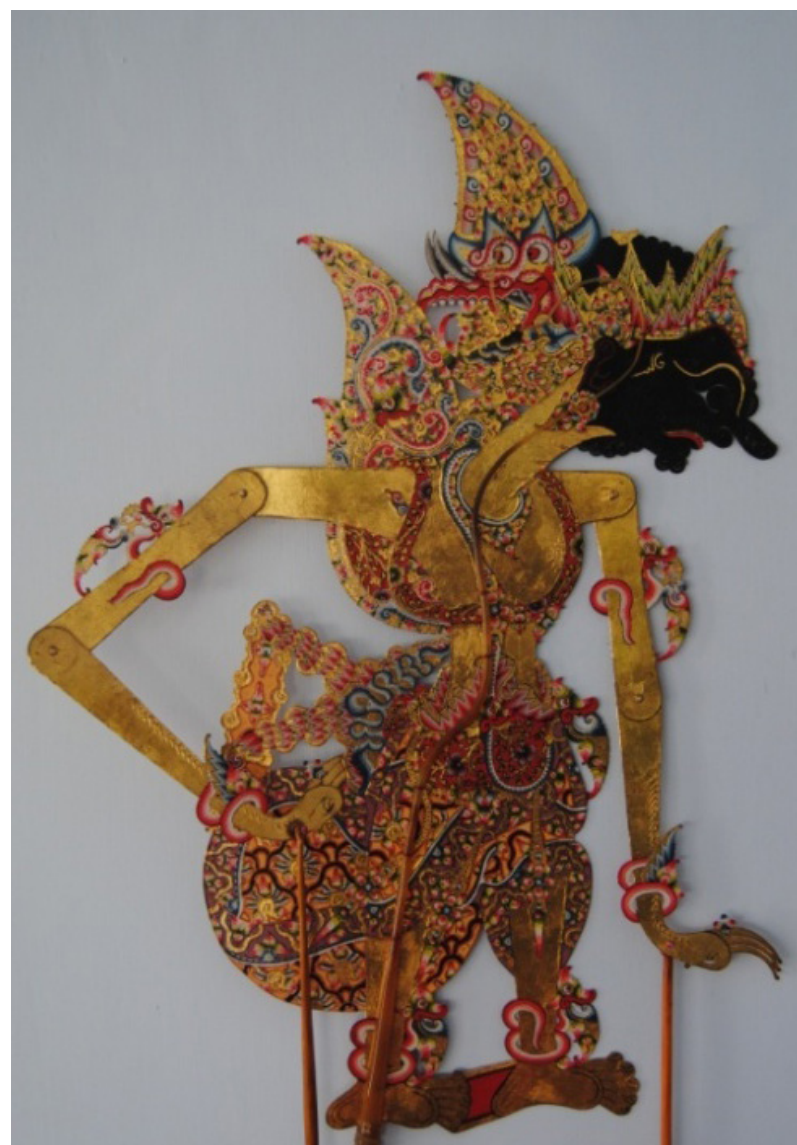

Gambar 1. Tokoh wayang Prabu Duryudana yang memiliki sifat ragu-ragu dan sombong, ketika jejer diiringi Ketawang Gendhing Kabor, koleksi Teguh Biantoro.

(Foto: Junaidi, 2011) $\begin{array}{llllllll}.65 & 3356 & 2321 & 6532 & \ldots 23 & 6532 & 5323 & 5616\end{array}$

$\begin{array}{lllllll}0653356 \quad 2321 \quad 6532 & \ldots 23 \quad 6532 & 5323 \quad 5616\end{array}$

33.. $33 \ldots 33.2 \quad 5321 \ldots 61123 \quad 6532 \quad .126$

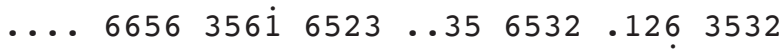

$\begin{array}{llllllll}5653 & 2126 & 356 i & 6523 & \ldots 35 & 6532 & .126 & 3532\end{array}$

$\begin{array}{llllllll}5653 & 2126 & 3561 & 6523 & \ldots 35 & 6532 & .126 & 3532\end{array}$

$\begin{array}{llllllll}5653 & 2126 & 356 i & 6523 & \ldots & 1123 & 6532 & .126\end{array}$

Ompak inggah

$\begin{array}{lllllllll}.5 .3 & .5 .3 & .5 .3 & .2 .1 & .2 .3 & .2 .1 & .2 .1 & .5 & .3\end{array}$

Inggah

$\begin{array}{llllllllll}.5 .3 & .2 .1 & .2 & .3 & .2 .1 & .2 .3 & .2 .1 & .2 .1 & .5 .3\end{array}$

$\begin{array}{llllllll}.5 .3 & .2 .1 & .2 .3 & .2 .1 & .2 .3 & .2 .1 & .2 .1 & .5 .3\end{array}$

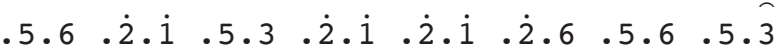

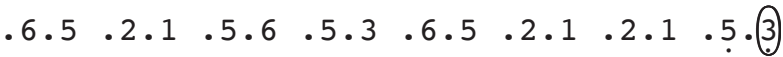

(Walidi, 1977: 18)

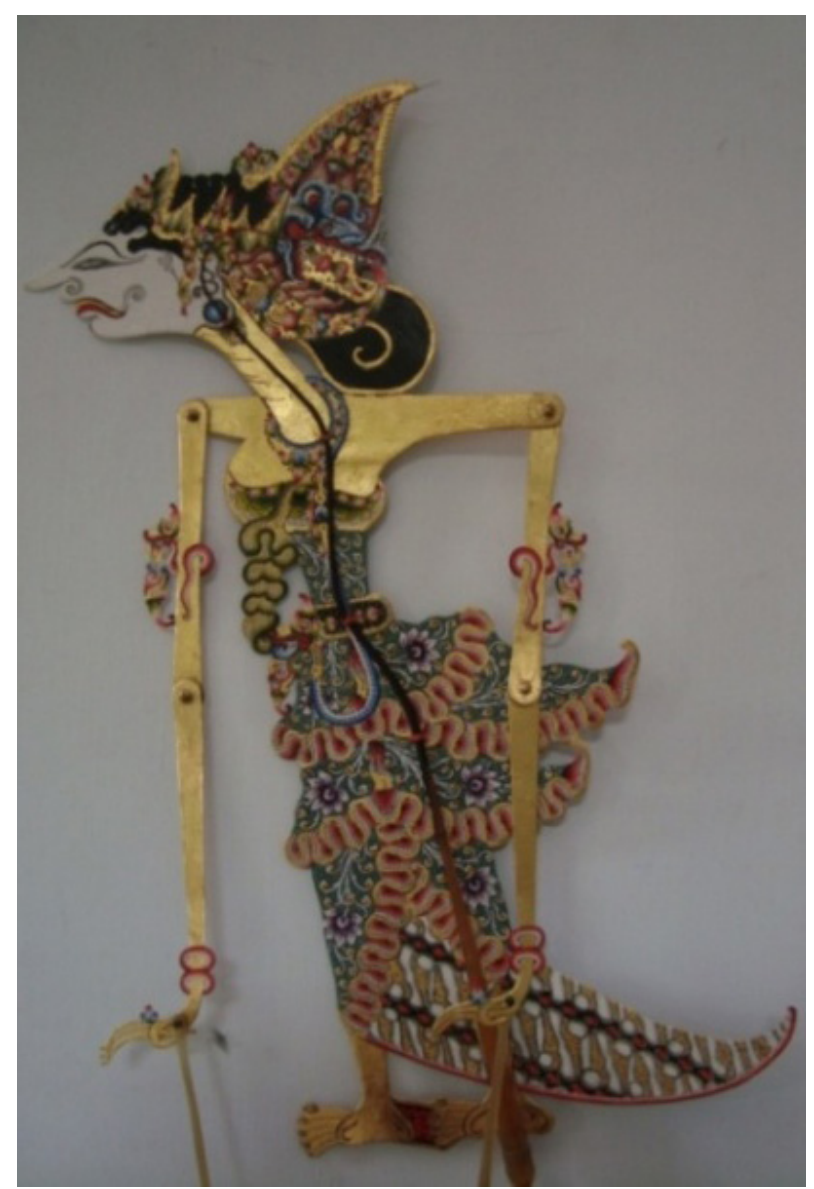

Gambar 2. Tokoh wayang Dewi Banowati wanda golèk, yang diiringi dengan Gendhing Damarkèli, koleksi Junaidi. (Foto: Junaidi, 2011) 


\section{Korelasi Gending dengan Wayang}

Seperti telah dikemukakan di depan bahwa tokoh wayang dan gending memiliki relasi bentuk dan karakter. Bentuk di sini lebih difokuskan pada ukuran wayang dan ukuran gending, sebagai contoh Prabu Duryudana adalah tokoh wayang lakilaki bertubuh tinggi besar (gedhé dhuwur/gagah) atau wayang besar (wayang gedhé), setara dengan tokoh Bratasena, Boma, dan sebagainya (golongan wayang ukuran besar/gedhé) (Junaidi, 2012: 57), jika dijajarkan pada panggungan (disimping) berada di belakang Baladewa (Sajid, 1958: 27), atau di belakang Bratasena dan di depan Gandamana. Tatacara pemajangan wayang simpingan adalah diurutkan mulai dari wayang ukuran paling besar (paling gedhé) atau sakButa Raton (Raja Raksasa), besar (gedhé) atau sakWerkudara sampai sakBratasesna/sakButa Patih sampai sakDuryudana (Patih Raksasa), magak atau sakGandamana sampai sakAntasena/sakKurupati sampai sakSeta, tanggung atau sakBatara Guru sampai sakPremadi/
sakBasudewa sampai sakSuryatmaja, sedang atau sakNakula, kecil (cilik) atau sakputrèn (putri), dan diakhiri paling kecil (paling cilik) atau sakBayèn (bayi). Simpingan sebagai pengurutan ukuran wayang dimulai dari ukuran paling besar, besar, magak, tanggung, sedang, kecil, dan diakhiri paling kecil dapat dilihat pada gambar 3 dan gambar 4 .

Wayang simpingan terdiri atas dua bagian, yaitu: (1) simpingan kanan, dan (2) simpingan kiri. Simpingan kanan terdiri atas tokoh raja, patih, ksatria, putri, bambangan, dan anak kecil (bayènl bayi) yang pada umumnya berwujud dan karakter baik, sedangkan simpingan kiri terdiri atas tokoh raja, patih, ksatria, dan bambangan, yang pada umumnya berwajah dan karakter jelek. Namun demikian, terdapat tokoh wayang berwajah dan berkarakter baik berada di kiri, seperti Abimanyu karena termasuk wayang jangkahan (jarak telapak kaki depan dan belakang lebih lebar), juga sebaliknya terdapat tokoh wayang berwajah dan berkarakter jelek berada di kanan, seperti Durga atau bidadari (wanita).

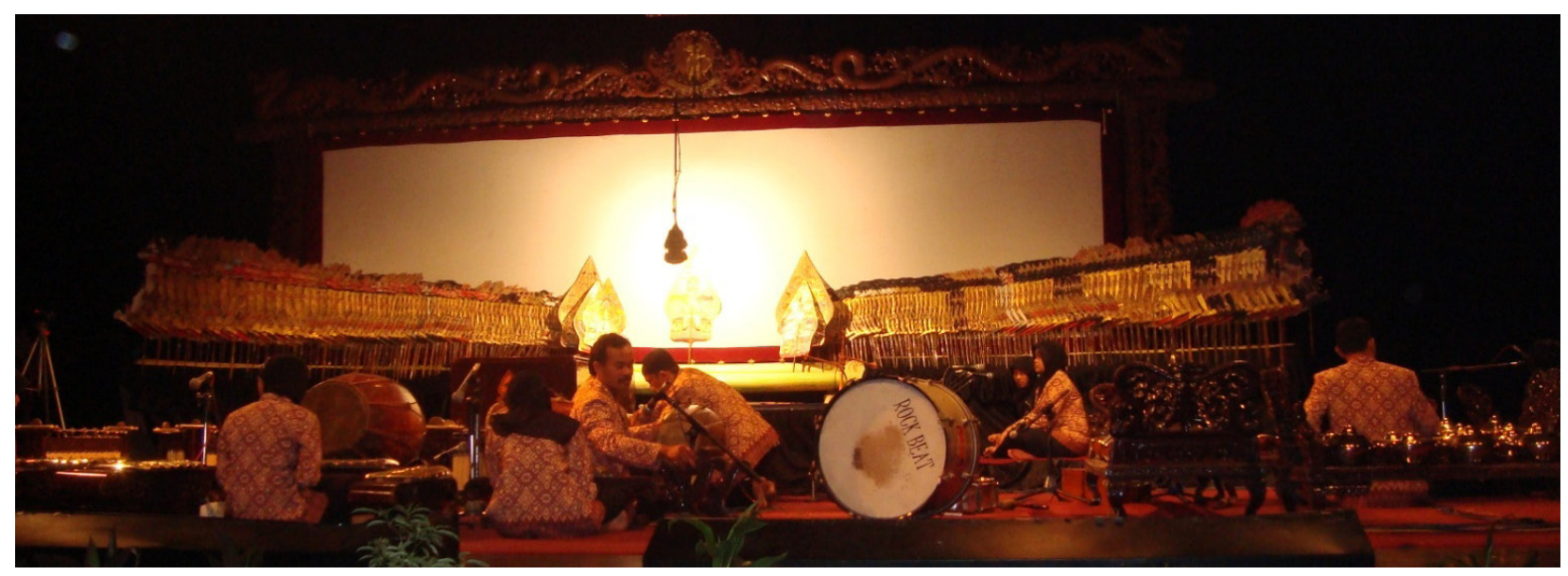

Gambar 3. Wayang simpingan kanan dan kiri. (Foto: Junaidi, 2009)

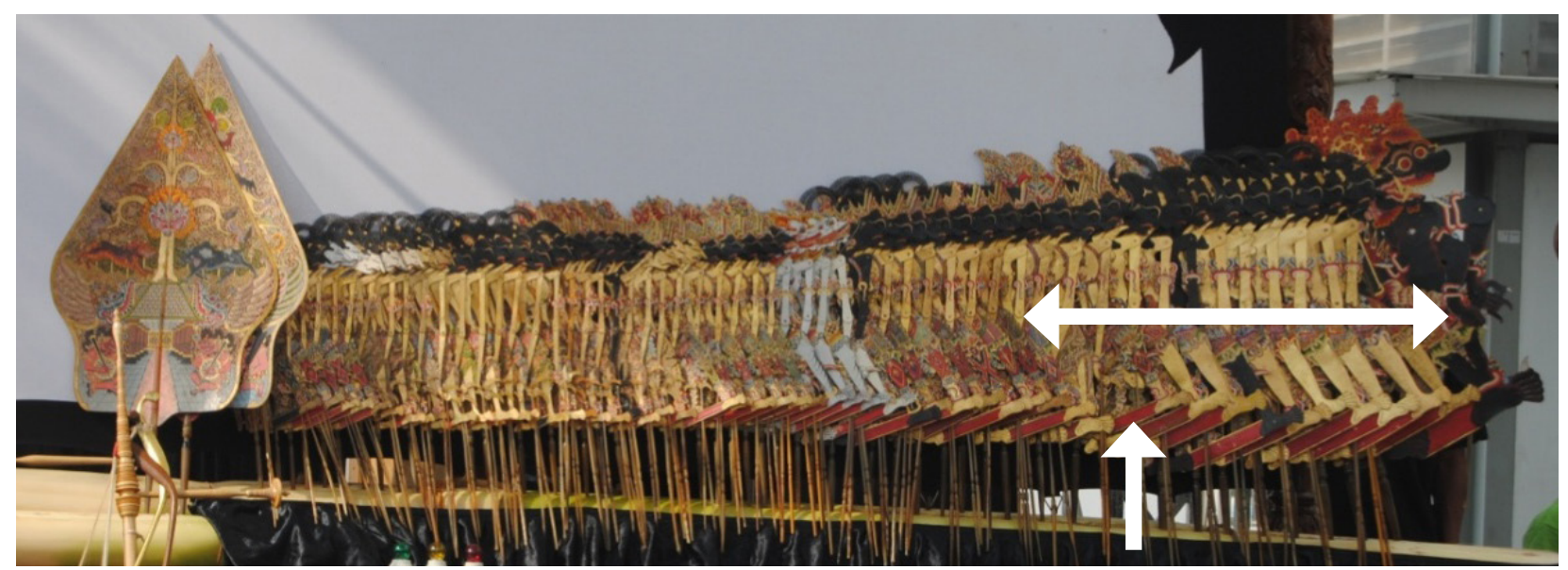

Gambar 4. Tokoh wayang Duryudana ketika ditempatkan pada simpingan. (Foto: Junaidi, 2012) 
Kembali pada pembicaraan hubungan antara bentuk wayang dan gending pendukungnya, wayang Dewi Banowati di sini akan diambil sebagai contoh. Dewi Banowati merupakan tokoh wayang perempuan bertubuh tinggi besar (gedhé dhuwur) mbombrong) (Junaidi, 2012: 66), bahkan paling besar di antara wayang putrèn (perempuan) lainnya, sehingga keduanya termasuk wayang berukuran besar (wayang gedhé) di dalam kelompoknya. Ukuran fisik tubuh Dewi Banowati tersebut secara eksplisit diungkapkan dalam janturan adegan kedhatonan dan cakepan/syair sulukan sendhon kloloran, yaitu "Sanadyan ambombrong Banowati mundhak ayuné ('biarpun tubuhnya gemuk dan tinggi tetapi menjadi semakin cantik') (Wignyasoetarna, 1996: 17), atau "Sembada kang adedeg manda rangkung ('sembada karena ukuran tubuhnya tinggi dan besar') (Probohardjono, 1966: 14). Oleh karena ukurannya lebih tinggi dibanding dengan wayang putri lainnya, maka posisinya berada di urutan wayang putri. Gambar 5 memperlihatkan posisi tokoh Dewi Banowati dalam wayang simpingan.

Seperti dikatakan di depan bahwa tokoh Dewi Banowati wanda golèk didukung gending Damarkèli dalam pengadegannya. Gending Damarkèli adalah golongan gending yang berukuran besar (gendhing gedhé), yaitu berbentuk kethuk papat kerep minggah wolu, maksudnya berjumlah 128 ketukan atau sabetan dalam satuan bunyi gong (sakgongan), terdiri atas empat kali bunyi kethuk pada garap mérong (ketukan keempat, keduabelas, keduapuluh, dan keduapuluh delapan), sedangkan pada garap inggah terdiri atas bunyi kethuk delapan kali (ketukan kedua, keenam, kesepuluh, keempatbelas, kedelapanbelas, keduapuh dua, keduapuluh enam, dan ketigapuluh) dalam setiap tabuhan kenong (sakkenongan) atau tigapuluh dua ketukan. Dengan demikian, antara tokoh wayang dan gending pendukungnya memiliki relasi atau hubungan bentuk yang seimbang, yakni berukuran besar. Hubungan ini disebut relasi mungkus atau membingkai (Waridi, 2005: 17-59). Konsep mungkus adalah memberikan tempat atau wadah suatu isi, yakni isinya tokoh wayang atau adegan, sedangkan tempat atau wadahnya adalah gending.

Korelasi wayang dengan gending dipandang dari segi karakter, yaitu penyesuaian antara karakter tokoh wayang dengan karakter gending pendukungnya. Pertalian pertama bersifat nglambari (ilustrasi) dan keduanya bersifat nyawiji (menyatu) (Waridi, 2005: 17-59). Tokoh-tokoh wayang memiliki karakter berbeda-beda, seperti misalnya penyabar (sabar), emosional (getapan), sombong (umuk), kejam (wengis), penurut (manut),
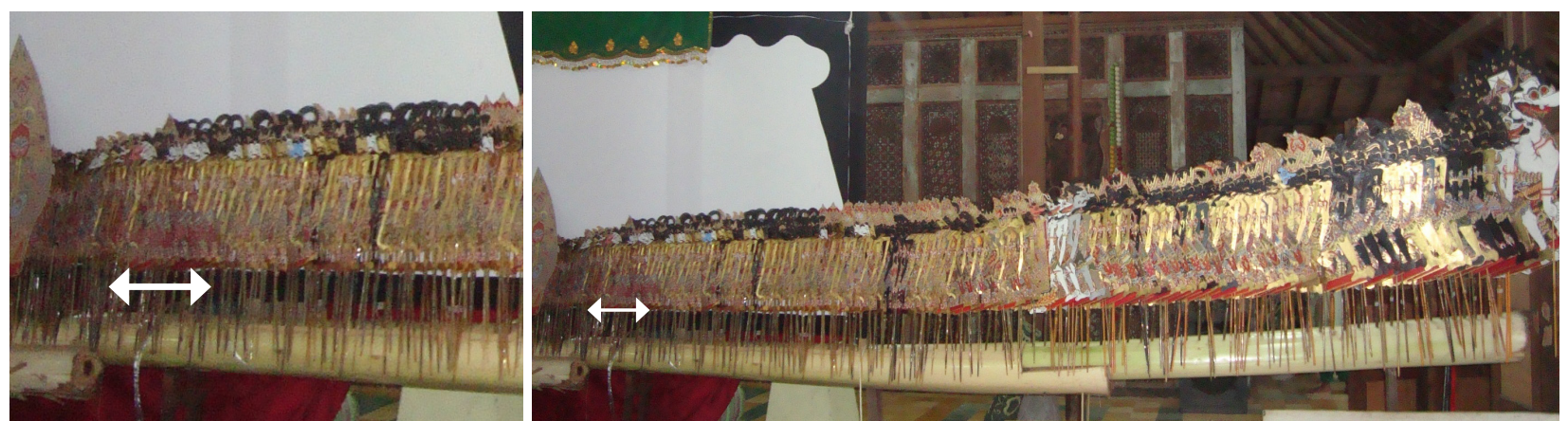

Gambar 5. Posisi Dewi Banowati berada di urutan paling depan untuk kelompok wayang putri (kiri) dan merupakan bagian dari wayang simpingan kanan (kanan) (Foto: Junaidi, 2007)
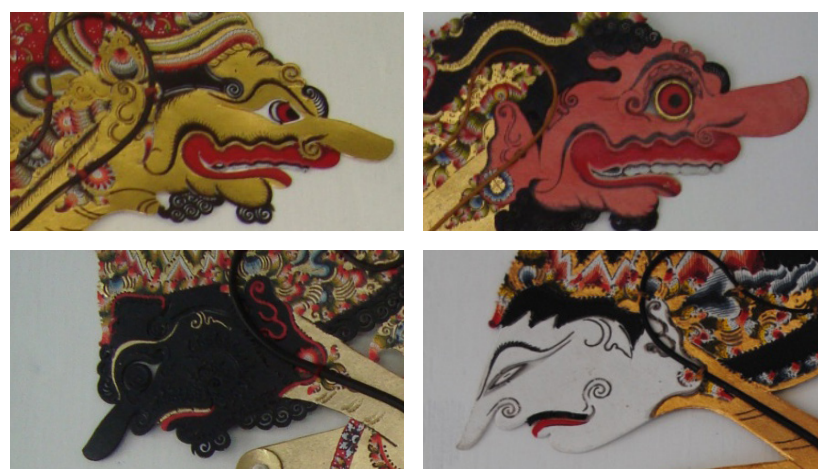

Gambar 6. Wujud atau bentuk wajah tokoh wayang yang men
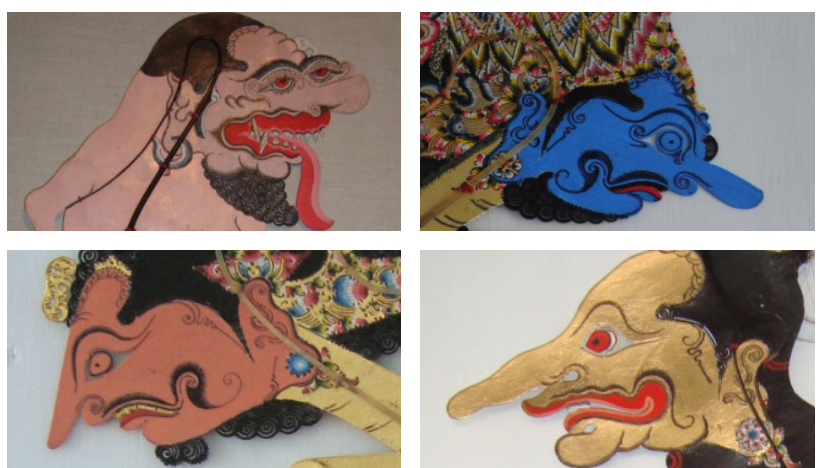
jujur (jujur), licik (culika), dan sebagainya. Karakter tersebut diungkapkan dengan bahasa yang dinarasikan oleh dalang berupa janturan, pocapan, ginem, suluk, dan tembang (visual naratif). Contohnya seperti misalnya pada janturan adegan babak unjal dengan raja sebrang Prabu Susarma dari negara Trigarta: "Éling-éling ratu sabrang ingkang kirang ing subasita kaduk sembrana remenané pamèr kasugihan, kaprawiran miwah kalungguhan" ('maklum raja seberang kurang sopan santun kelewat latah senang pamer kekayaan, kesaktian, dan kedudukan') (Junaidi, 2012: 114). Maka gending untuk mendukungnya juga berkarakter sombong atau glamour, yaitu Ladrang Moncèr yang artinya tersohor. Dengan tokoh yang bersifat sombong maka gending pendukungnya juga memiliki karakter lebih tinggi, sehingga tercipta hubungan karakter yang bersifat nyawiji (menyatu), yaitu sama-sama berkarakter sombong atau merasa lebih tinggi.

Di samping itu, karakter diungkapkan melalui wujud tokoh wayang terfokuskan pada wajah atau raut muka (prapupan), yakni bentuk (baik 'apik' dan jelek 'èlèk) dan warna (merah = emosional, putih $=$ kejujuran, kuning $=$ periang, dan hitam $=$ ketenangan). Macam-macam bentuk muka tokoh wayang dapat dilihat pada gambar 6. Dengan demikian, wujud dan pewarnaan wajah wayang dapat dijadikan sebagai penanda karakternya. Dengan melihat wujud dan rupa wajah tokoh wayang dapat dipahami sifat dan karakter dasarnya, sehingga didukung dengan gending yang dapat dijadikan sebagai landasan atau lambaran untuk mengungkapkan kemantapan rasa atau suasana tokoh dalam setiap adegan. Seperti misalnya tokoh wayang Sengkuni yang memiliki sifat dasar culas dan licik didukung dengan gending Ladrang Léré-léré, yang artinya kotor atau licin, sehingga kalimat sandi dari gending (sasmita gendhing) tersebut menunjukkan sesuatu hal yang tidak baik atau dapat menemui kejadian yang tidak baik atau celaka. Adapun bunyi sasmita gendhing tersebut berbunyi: "kaya keplèsèd-plèsèda"'seperti akan selalu tergelincir' (Widodo, 1975: 6)

\section{Penutup}

Berdasarkan pembahasan tersebut di atas, maka gending dalam pakeliran wayang kulit purwa gaya Surakarta memiliki fungsi yang sangat penting, yakni dapat mendukung adegan dan tokoh wayang yang ditampilkan dalam setiap lakon, karena memiliki korelasi bentuk dan karakter. Hubungan bentuk bersifat ukuran, wujud, dan warna, sedangkan hubungan karakter bersifat linguis, yakni melalui kata-kata dan kalimat yang diucapkan oleh dalang berupa janturan, pocapan, dan ginem. Secara visual korelasi tersebut dapat dipahami melalui pocapan sasmita gendhing (ucapan kalimat sandi bagi seorang dalang untuk memberi aba kepada pengrawit tentang gending yang akan dimainkan untuk mendukung tokoh wayang yang akan dimunculkan). Hadirnya gending-gending dalam pakeliran tersebut dapat memperjelas suasana pakeliran yang dikehendaki oleh dalang, sehingga penting sekali diapresiasi oleh para pengrawit dan dalang, agar sajian pertunjukan wayangnya tercapai secara estetis, teknis, dan filosofis.

\section{Kepustakaan}

Junaidi. 2010. "Pakeliran Wayang Kulit Purwa Gaya Surakarta oleh Dalang Anak". Yogyakarta: Disertasi untuk Memperoleh Sarjana S-3, Program Pengkajian Seni Pertunjukan \& Seni Rupa, Sekolah Pascasarjana, Universitas Gadjah Mada.

Junaidi. 2011. Wayang: Sebagai Media Pendidikan Budi Pekerti bagi Generasi Muda. Yogyakarta: Arindo Nusa media.

Junaidi. 2012. Wayang Kulit Purwa Gaya Surakarta: Ikonografi \& Teknik Pakelirannya. Yogyakarta: Badan Penerbit ISI Yogyakarta.

Junaidi. 2014. "Modul Pembelajaran Seni Pedalangan Gaya Yogyakarta untuk Guru Sanggar". Makalah pada pelatihan seni pedalangan gaya Yogyakarta oleh PEPADI dan Yayasan TOTAL, tanggal 22-24 di Sanggar Seni Pondok Tingal, Borobudur, Magelang, Jawa Tengah.

Kusumadilaga, KPH. 1981. Serat Sastramiruda. Terj. Kamajaya dan dialihaksarakan oleh Sudibyo Z. Hadisucipto. Jakarta: Proyek Penerbitan Buku Sastra Indonesia dan Daerah, Departemen Pendidikan dan Kebudayaan.

Nojowirongko, M. Ng. 1960. Serat Tuntunan Padalangan Lampahan Irawan Rabi. Jogjakarta: Tjabang Bagian Bahasa Jogjakarta 
Djawatan Kebudayaan, Departemen P.P. dan K.

Panenggak Widodo, Ki Marwoto. 1975. Balungan Ringgit Purwa Mawi: Busananing DhalangGendhing-Pratélan Gendhing/Sulukan. Sala: Toko Buku K.S.

Panenggak Widodo, Ki Marwoto. 1990. Tuntunan Ketrampilan Tatah Sungging Wayang Kulit. Cetakan II. Surabaya: PT. Citra Jaya Murti.

Probohardjono, S. 1957. Gending-Gending ingkang kangge Nabuhi Wajang Purwa. Ngasem-Jogja: Usaha Penerbitan P.T. Sinduniti.

Probohardjono, S . 1966. Sulukan Sléndro. Surakarta: CV. Ratna.

Sajid, RM. 1958. Bawwarna Wayang. Jogjakarta: PT. Pertjetakan Republik Indonesia.

Siswoharsoyo. Ki. 1982. Pakem Pedhalangan Lampahan Makutharama. Ngayogyakarta: Toko Buku S.G.
Supanggah, Rahayu, 2009. Bothèkan Karawitan II: Garap. Surakarta: Program Pascasarjana bekerja sama dengan ISI Press Surakarta.

Suyanto, Ed. 2007. Teori Pedalangan: Bunga Rampai Elemen-Elemen Dasar Pakeliran. Surakarta: ISI Surakarta dan Percetakan CV. Saka Production.

Walidi. 1977. Gending-Gending Wayang Purwa. Surakarta: Akademi Seni Karawitan Indonesia, Departemen P \&K.

Waridi. 2005. Karawitan Wayang Kulit Purwa Gaya Surakarta. Jakarta: Sekretariat Nasional Pewayangan Indonesia.

Wignyosoetarno, Ng. 1977. "Pakem Makutharama”. Surakarta: Pasinaon Dhalang Mangkunagaran.

Wignyosoetarno, Ng. 1996. Serat Pedhalangan Lampahan Wahyu Pakem Makutharama. Surakarta: STSI Press. 